Some progress on the law of the sea

An indication of the slowness of the rate of progress at Geneva in the Third UN Conference on the Law of the Sea is the fact that at least two more sessions are now envisaged; the next will be convened in a year's time at UN Headquarters in New York. Little likelihood is therefore seen of an acceptable convention being hammered out before the end of 1976 at the earliest and it could not possibly come into force for at least two years after that. Progress has definitely been made, however, not least with the proposals covering scientific research.

DELAY has its dangers and there is still a strong possibility of a complete collapse of the negotiations on the law of the sea, which would be disastrous for developed and developing countries alike. Appeals have once again been made for countries to resist the temptation to take unilateral action before agreement is reached, though the patience of some of them is wearing thin and each year is likely to see further arbitrary claims being placed on statute books by geographically advantaged countries, such as the Latin American States, the USA and Iceland, followed by Canada, Mexico and Norway. Fortunately most nations are, so far, showing definite signs of restraint in staking their claims.

One of the chief stumbling blocks to negotiation is the multiplicity of groupings. It is not a case of two groups of states, 'developing' and 'devcloped', with clear negotiating positions. There are the geographically - advantaged (Argentine, Brazil, Canada, Kenya, the UK, the USA, and so on) and the geographically disadvantaged (led by The Netherlands), the coastal and the land-locked, the shelf locked, the island states, the archipelagic states and so on, all with different needs, wishes and ideas; each grouping overlaps inextricably with the others. There is little doubt that time is on the side of the geographically advantaged states-the concept of the "Common Heritage of all Mankind' has been severely mauled and is unlikely to survive, except in a very weak and hardly recognisable form; this is mainly because of the activities of geographically advantaged developing states, rather than deve- loped ones, though Canada has been conspicuously present at the kill.

Negotiating should now start in earnest both in the inter-sessional period and at the next session, though the stated likelihood of a further session after New York "if needed" in summer 1976 will tend to discourage such a move. Three weeks before the end of the conference, however, the chairmen of the three committees were asked to prepare an informal single negotiating text to serve as a procedural device to provide a basis for negotiation. This appeared on the last day of the session and, following scenes of copy snatching from other delegations' pigeon holes, the delegates departed to reconsider and reformulate their positions in preparation for the next occasion. It is vitally important that countries accept this text as a basis for negotiation; if they do not, there is little hope to be seen for any agreement in the foresecable future.

Countries are still tending to wait for the so-called negotiating phase and, as a result, statements in public often differ quite considerably from the views put forward by the same delegate informally outside a meeting. One of the most surprising positions is that of India, which has in the past benefited almost more than any other developing country from international marine scientific research projects such as the International Indian Ocean Expedition but has been one of the leaders (in public) of the hardliners against any compromise on scientific research in the oceans. There should, in India's view, be no scientific research without very close control by the coastal state or an international authority.

The right to carry out marine scientific research suffered so much from a number of strong statements both for and against that the Chairman of the US Delegation (which came in for praise for the flexibility of its approach to the conference) stated in his closing statement, "I am particularly dismayed by continuing attempts to place restrictions on the conduct of marine scientific research. Knowledge of the oceans is important to all of us. Good science is free science; it is not a commodity that can be packaged and purchased in predetermined quantities. The conference should concentrate on means to ensure that all will enjoy the fruits of science, not on means to restrict science for fear it will only benefit the few".

Shortly before the end of the conference, and it was almost as if this document had not been noticed by the USA (or perhaps the Chairman of the Delegation had finalised his statement by then), a most unlikely group of developing countries, led by Mexico, which country has shown throughout an excellent grasp and understanding of the problems involved, presented a highly skilled compromise document entitled Draft Articles on Marine Scientific Research. This document has avoided most of the pitfalls which have proved unacceptable to one faction or another and should provide a real basis for the relevant part of the convention. Certain of the articles are, however, likely to be used by the developing countries as negotiating elements for improved arrangements for Transfer of Technology, including training and education in the marine sciences.

One of the strengths of this text is the way in which the controversial matter of fundamental as against resource-related research, has been dealt with. The onus is now placed on the coastal state involved to decide under which category an outsider's research programme falls. No doubt something like $90 \%$ of marine research will fall in the resource-related category but rules for conduct of such research, with the full consent and participation of the coastal state, are also provided for.

Unfortunately the author of the informal single negotiating text had failed to appreciate this approach and had gone back to some of the earlier, less informed proposed texts which call for the promotion "through competent international organisations of the establishment of criteria and guidelines concerning the differentiation between research directly related to the exploraion and exploitation of the living and non-living resources and fundamental research which is not directly related to exploration and exploitation of such resources"-a virtually impossible task. This text also still contains the fundamental error of linking exploration and exploitation, two completely different activities which should have separate regulations governing them. The former should be encouraged by all, in particular the developing countries, the latter clearly needs close supervision to ensure that any consequent profits are equitably distributed, that renewable resources are not destroyed in the process, that coastal states' rights are fully taken into account and so on.

The other bright spot in the conference has been the work done by an informal group chaired by Minister Jens Evensen of Norway which has developed a series of texts of draft articles on the 200-mile economic zone. This group of senior delegates from about a third of the countries present has had to deal with many diverse matters and interests, such as full use of fish stocks, size of allowable catches, historical rights, access to resources by other countries and so on. These will all be used as negotiating points in what will probably be the key to the 
convention, as most developing countries are more interested in immediate ranefits which are seen to lie in their economic zones than more distant and less identifiable goals. No agreement on the economic zone will mean no convention. So far, however, the landlocked countries, which consist of two factions - those from Europe (like Switzerland and Austria) and the dozen or so from Africa-and the geographically disadvantaged states, consider that their interests have not yet been sufficiently taken into account.

Far more sinister are the activities propcsed in the negotiating text for an International Seabed Authority. For instance, under a paragraph entitled "Contracts for Associated Operations", it says, "the Authority may enter into a contract, joint venture or any other such form of association, for the conduct of scientific research, or for the carrying out of a general survey or exploration of the Area ..." It seems that under these plans the authority would have the right to deny access to the sea bed or to charge heavily for it. The structure proposed in the draft articles for the authority would be large and costly; in fact, it would virtually amount to the setting up of another new UN body which, in the present economic climate, many countries are determined to avoid. Certain of these countries would be prepared to see an authority formed provided it was self-supporting; that is, if its costs were covered by its income from contracts and exploitation licences. The most optimistic estimates are only for three or four contracts a year in the internatinal zone for the foreseeable future and this would certainly not maintain an authority of the size envisaged. Almost certainly the conference will soon start to look to the existing UN bodies, to see if one of them, such as the Intergovernmental Oceanographic Commission (IOC) or the InterGovernmental Maritime Consultative Organisation (IMCO), could be expanded to take on additional tasks or if a new grouping could be formed.

It is clear from the Geneva manoeuvrings and deliberations that the chief interests of the developing countries lie, quite rightly, in the exploitation of living and mineral resources in the economic zone and in Transfer of Technology. Marine scientific research, instead of being called for urgently, is looked on with suspicion by countries who should know better and is being lumped with such matters as Coastal State Control of Ship-generated Pollution, the setting up of the International Sea-bed Authority for the International Zone, and numerous other matters of lesser interest which will be used as bargaining counters for immediate benefits.

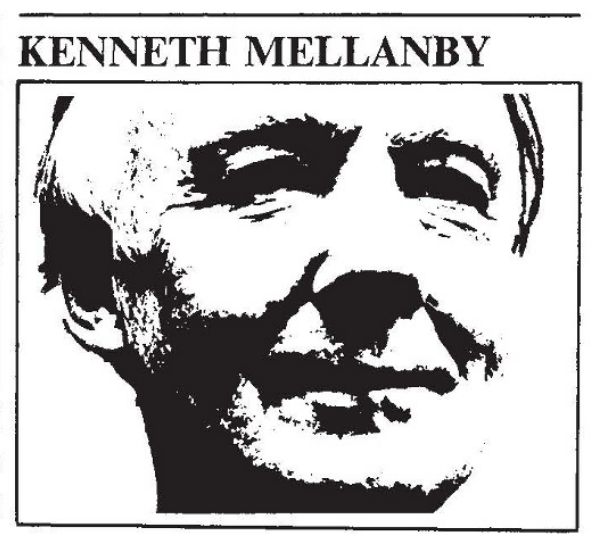

\section{Weather vein}

$\mathbf{r} r$ is a common experience that when a subject which has previously caused us little concern comes to our serious notice, we seem to find ourselves hearing about it repeatedly. In my own recent experience, climatology is such a subject. In February this year I went to the island of La Gomera in the Canaries, to advise on possible agricultural and other developments. My remit was that developments should not adversely affect the ecology of the environment and should, if possible, encourage native flora and fauna.

La Gomera is nearly circular, some 12 miles in diameter, and it rises sharply to a height of nearly 6,000 feet in the middle. The highest land is covered by the remains of the original forest, most areas have been terraced and cultivated (though many farms have been abandoned) and the population is decreasing. For some years the weather has been unusually dry, and this February-at the end of what should have been the wet season, though little rain fell-the land was parched except where there was irrigation and the tanks, intended for use during the dry summer, were empty.

There are undoubtedly substantial water deposits on the island, but we do not know their capacity, nor how long they will be able to continue to supply fresh water before this is seriously contaminated with salt from the surrounding and underlying seawater. With a good rainfull, such as occurred fairly regularly until recently, the deposits were recharged.

A local consultant is optimistic, claiming that the sunspot cycle will ensure adequate rain in the next 18 months. Other experts are not so sanguine, however. To make a rational plan, climatological information is desperately needed. On it depends the future for the local farmers as much as that for those concerned with a very interesting and unusual development. La Gomera is only a tiny island, but it does epitomise a problem affecting vast areas in many continents, not least those of the Sahel area in adjacent Africa.

I had this example in mind when I attended a recent forum on "Neglected Research", where I heard how the pioneer work of Professor H. H. Lamb's Climatology Unit in the University of East Anglia had been completely denied support from any of the research councils. Yet when I was working on the water problems of $\mathrm{La}$ Gomera, I found that expert opinion, not only in Britain but also in other countries, always came back to the recognition of our current ignorance, and to the long-term importance of the work being tackled at Norwich by Lamb and his colleagues. It is difficult to understand why support is denied to a unit concerned with such an important and practical problem area, in which there is a good chance of some success.

It is generally believed that we in Britain have evolved the fairest and least corrupt method for sharing out research funds, even if it is so timewasting. Many of our most eminent scientists sit day after day on the committees which make the recommendations on how grants should be given or withheld. This thankless task is carried out with care and, if possible, without undue bias. It would be cynical to suggest that those who give up so much of their time do so, partly, because this increases their chances of securing a substantial sum for their own work or for that of their department. It is true that we read in the minutes-"Professor Blank retired during the discussion of this item"-and then, surprise, surprise, follows the announcement that Blank's application for $£ 50,000$ has been successful. After all, Blank was put on the committee because of his expertise, and he would obviously not put forward a silly proposal! And occasionally a member's application is turned down. Yet the Lamb incident shows that our situation is not perfect. Even more serious, many unsuccessful and trivial research proposals do receive substantial support, and there is little to show for it.

In a field like research where chance plays so large a part, the very care with which we approach the problem may be a cause of its imperfections. I know, from my own experience, that one of the most substantial grants which led to marked research productivity was given on the whim of a minister and not on the advice of an expert committee. The trouble today is that such large sums of money are involved that we tend to build in complications which may waste much of that money. We forget that original research was once comparatively inexpensive. A plea for more small grants for unfashionable studies might produce unexpected results. 